\title{
BARRIER PERFORMANCE OF SILANE-CLAY NANOCOMPOSITE COATINGS ON CONCRETE STRUCTURE
}

\author{
Ricky S.C. Woo ${ }^{1}$, Honggang Zhu ${ }^{2}$, Michael M.K. Chow ${ }^{1}$, Christopher K.Y. Leung ${ }^{2}$ \\ and Jang-Kyo Kim ${ }^{1 *}$ \\ ${ }^{1}$ Department of Mechanical Engineering, ${ }^{2}$ Department of Civil Engineering \\ Hong Kong University of Science and Technology, Clear Water Bay, Hong Kong
}

\begin{abstract}
The barrier performance of silane/clay nanocomposites as a coating material on concrete structure has been evaluated under different accelerated weathering tests, including moisture permeability and salty water spray. The silane/clay nanocomposite was fabricated by curing the silane-organoclay mixture through hydrogen bonding with concrete. XRD analysis indicated an improved intercalation of clay after adding into the silane solution. SEM examination of the coated concrete surface confirmed that the nanocomposite can effectively cover the pores and voids present on the concrete surface. The rheological study revealed a linear increase in viscosity with the addition of clay. Wetting properties were evaluated via contact angle measurements. The moisture permeability test showed that the permeability was substantially reduced due to the presence of clay of high aspect ratio. The salty water spray tests indicated the distinct barrier characteristics of silane/clay nanocomposite coating on concrete structure.
\end{abstract}

Keywords: A coating; A nanoclay; A nano composites; B environmental degradation; B transport properties

*Corresponding author: Tel) 852-2358 7207; Fax) 852-2358 1543; Email) mejkkim@ust.hk

\section{Introduction}

The deterioration of concrete due to exposure to environment and mechanical loads requires continuous repair and rehabilitation. Among many degradation mechanisms, corrosion of steel rebar inside concrete is one of the most significant and detrimental. The chemical reaction in concrete produces calcium hydroxide, which provides an alkaline environment. Thus, a stable 
oxide film is formed on the steel surface, protecting the rebar from corrosion. However, the penetration of chloride ions, from sea water or de-icing salts, can break down the protective film and expose the steel bar to corrosion [1]. To delay the chloride penetration and hence to prolong the service life of concrete structures, surface treatment such as coating is commonly employed.

Silane has widely been applied to glass fiber surface as the coupling agent with polymer resins [2]. Silane, once applied as coating on concrete, penetrates into the concrete pores and thus forms an impervious layer on the surface. This protective action greatly improves the resistance to environmental attacks, such as chloride ions diffusion, water permeation [3,4]. Polymer-nanoclay composites have emerged as a new class of advanced organic-inorganic materials with excellent mechanical properties and barrier characteristics with only a few $\%$ of well-dispersed clay reinforcements $[5,6]$. Clay nanocomposites find many potential applications in civil engineering [7-9]. Apart from enhanced modulus, strength and fracture toughness, the nanoclay can offer an excellent barrier capability with significantly reduced permeability of chemicals, moisture and gases [10-12]. The reduction of chemical and moisture absorption can suppress the corrosion of reinforcing materials in concrete, giving rise to better long-term durability.

This paper is part of a larger project on clay nanocomposites with excellent moisture barrier properties for applications as adhesive, coating and matrix for fibre reinforced composites in construction. As a continuation of previous work [8-13], this paper studies the barrier characteristics of silane-clay nanocomposites that are applied onto concrete as the protective coating. Several accelerated weathering tests, including moisture permeability test and salty water 
resistance test, were employed to assess the performance of silane coating and organoclay reinforced silane nanocomposites, relative to that of plain concrete without a protective coating.

\section{Experiments}

\subsection{Materials and Sample Preparation}

The silane used in this work is SILRES BS 1701 (supplied by Wacker Silicones Inc.), a mixture of isomeric octyltriethoxysilane and isooctyltriethoxysilane as main components. The chemical structure of octyltriethoxysilane shown in Figure 1 indicates that the silicon atom is attached with three hydrolyzable alkoxy groups and an organofunctional group. Silane is normally applied as a water-repellent primer and hydrophobic impregnating agent for concrete. The silane reacts with atmospheric moisture or pore water in the concrete, generating active ingredient to lower the water absorbency of the treated concrete.

Two types of montmorillonite-based clay with different organic modifiers (Figure 2), namely Cloisite 20A (dimethyl dehydrogenated tallow quaternary ammonium modified, supplied by Rockwood Specialties) and I.30P (primary octadecylamine modified, supplied by Nanocor Inc.) were added into silane to prepare nanocomposites. The clay-silane mixture was ultrasonicated (Ultrasonic Processor XL2020) at $70 \mathrm{~W}$ and $42 \mathrm{kHz}$ for $3 \mathrm{~h}$, and was applied as coating onto concrete surface, which was cured at room temperature for at least 7 days before test. The surface morphologies of concrete surfaces with and without coating were examined using a scanning electron microscope (SEM, JEOL 6300).

\subsection{Characterization of Nanocomposites}

The silane/clay mixtures after ultrasonication were analyzed on an X-ray diffraction analyzer 
(XRD, Philips PW1830) that consisted of a $\mathrm{Cu}$ anode and a graphite monochromator to measure the intergallery distance of organoclay before and after the incorporation into silane. XRD spectra were obtained at room temperature on a $\theta-\theta$ diffractometer equipped with an intrinsic germanium detector system using $\mathrm{Cu} \mathrm{K \alpha}$ radiation $\left(1.540562 \AA\right.$ ) at a scanning rate of $0.01^{\circ} / \mathrm{min}$ from $2^{\circ}$ to $6^{\circ}$. Differential Scanning Calorimetry (DSC, DSC 92 Setaram 90/39324) was used to study the curing behaviour of silane with the application of heat from around room temperature to $240{ }^{\circ} \mathrm{C}$ at a heating rate of $10{ }^{\circ} \mathrm{C} / \mathrm{min}$ in a nitrogen environment. Any sudden change in heat flow would indicate the physical transformation of the material. The viscosities of the silane-clay mixtures with different clay contents were measured on a rotational rheometer (Paar Physica US 200) with controlled shear rates at room temperature. The applied torque was measured to rotate a spindle at a constant speed of $200 \mathrm{rpm}$ while immersed into the sample fluid of about $6 \mathrm{~g}$.

Wetting properties of silane containing different types and contents of organoclay were determined by static contact angle measurement at room temperature using a goniometer, with an accuracy of $\pm 0.2^{\circ}$. A single droplet of 2 to $4 \mu l$ was dispensed at a time on the substrate surface of engineered cementitious composite (ECC) concrete using a motorized syringe. The ECC concrete was prepared from cement mortar consisting of water: cement: sand $=0.6: 1$ : 0.6 by weight ratio and PVA fiber: cement mortar $=0.02: 1$ by volume ratio, which was moist-cured at 25 ${ }^{\circ} \mathrm{C}$ and $98 \% \mathrm{RH}$ for 14 days. The average contact angles were recorded immediately after the droplets touched the substrate and at least 5 measurements were conducted for each test. The theoretical considerations of wetting are based on the Young-Dupre equation [14] that defines the 
work of adhesion, $\mathrm{W}_{\mathrm{a}}$, between the liquid and solid as a function of contact angle $\theta$ :

$$
W_{a}=\gamma_{S}+\gamma_{L}-\gamma_{S L}=(1+\cos \theta) \gamma_{S L}
$$

where $\gamma_{S}$ and $\gamma_{\mathrm{L}}$ are the surface free energies of the solid and the liquid, respectively; and $\gamma_{\mathrm{SL}}$ is the interfacial free energy. The thermodynamic work of adhesion is defined as the work required to separate the interface between two phases from their equilibrium states.

\subsection{Accelerated Weathering Tests}

The salty water spray resistance test was performed according to Model Specification for Protective Coatings for Concrete, Appendix 4 from Civil Engineering Department of Hong Kong Government [15]. The moisture permeability test was performed according to the specifications ASTM E96 [16]. The test (shown in Figure 3) measures the moisture permeation rate through a hybrid layer of concrete and coating. This is an important assessment of coating material for its capability to act against the permeation of moisture that may lead to the degradation of mechanical and structural performance of reinforced concrete through corrosion of reinforcing steel bar $[17,18]$ as well as due to the combined effect of moisture and photo-degradation $[19,20]$. The ECC concrete square plate specimens with a coating on top were placed on an aluminium dish containing silica desiccant inside to ensure $0 \% \mathrm{RH}$. The edges of the specimens were sealed tightly with aluminium rings and silicone rubber to avoid leakage of water vapour and to fix the exposure area at $3600 \mathrm{~mm}^{2}$. The dish was then stored under the humid environment of $98 \% \mathrm{RH}$ and $25^{\circ} \mathrm{C}$, so that the moisture would permeate through the specimens and be absorbed by the desiccants inside the dish, leading to a gain in weight over an exposure time [10]. This method can thus directly 
simulate the practical situation, where the coating material acts as the barrier against moisture permeation into the concrete. The weight gain was recorded at every $24 \mathrm{~h}$ and the moisture permeability, $\mathrm{P}$, were calculated using the following equation:

$$
P=\frac{G / t A}{S\left(R_{1}-R_{2}\right)} \bullet h
$$

where $\mathrm{G}=$ water gain in $\mathrm{g} ; \mathrm{t}=$ exposed time in $\mathrm{h} ; \mathrm{A}=$ test area in $\mathrm{m}^{2} ; \mathrm{S}=$ saturation vapour pressure at the test temperature in $\mathrm{Pa} ; \mathrm{R}_{1}$ and $\mathrm{R}_{2}=$ relative humidity at test atmosphere $(98 \% \mathrm{RH})$ and inside the test dish $(0 \% \mathrm{RH})$ respectively; $\mathrm{h}=$ specimen thickness $(5.5 \mathrm{~mm})$.

In the salty water spray resistance test, artificial seawater was prepared with $50 \pm 5 \mathrm{~g} \mathrm{NaCl}$ salt dissolved in $1 \mathrm{~L}$ distilled/deionized water, according to the specification BS 3900:1985, Part F12. Normal strength concrete (water: cement: sand: aggregate $=0.76: 1: 2.5: 5$ by weight ratio) with ASTM type I Portland cement was used to make cylindrical specimens of $100 \mathrm{~mm}$ in diameter $\mathrm{x} 50 \mathrm{~mm}$ in length, as shown in Figure 4. The coatings were applied on one of the flat surfaces by brushing the coating solution. The surrounding concrete surface was encased with a $3 \mathrm{~mm}$ thick layer of epoxy resin to avoid the penetration of chloride ion during the spray test. The specimens were mounted in the spray cabinet with a set of salty water showers in front and tested for $1000 \mathrm{~h}$ under the following weathering cycle: $4 \mathrm{~h}$ salt water spray at $30{ }^{\circ} \mathrm{C}$ followed by $8 \mathrm{~h}$ drying at 25 $\mathrm{C}$ and $70 \% \mathrm{RH}$. After the completion of all the weathering cycles, the coated surface was washed with distilled water to remove the salt deposited on the surface, and then dried immediately. The penetration depth of chloride ion through the coating was determined in depth increment range of 6-8 $\mathrm{mm}$ up to $50 \mathrm{~mm}$ beneath the coating, by grinding up a concrete core obtained from the central 
$50 \mathrm{~mm}$ specimen diameter and analyzing the powder at various depths. The titration method for determining water-soluble chloride ion was used to measure the chloride ion content at each depth and three measurements were made to obtain the mean value.

\section{Results and Discussion}

\subsection{Dispersion State of Clay}

Figures 5 and 6 present the XRD spectra corresponding to the as-received clay powder and the silane/clay nanocomposites with varying clay types and loadings. Cloisite 20A and I.30P had an original intergallery distance of $2.49 \mathrm{~nm}$ and $2.24 \mathrm{~nm}$, respectively, as reflected from the peak of (001) basal plane. After mixing and subsequent ultrasonication, their peaks shifted to smaller angles indicating substantial increases in intergallery distance to around 3.4-3.7 nm, regardless of clay loadings. This suggests that the combination of mixing and ultrasonication promoted the insertion of silane molecules into the clay galleries and further swelling in the uncured state. The intergallery distance would be further enlarged during the curing reaction between the nanocomposite coating and concrete surface in order to maintain the thermodynamic equilibrium by driving silane molecules into clay layers before setting. XRD analysis on cured silane/clay nanocomposite coating was not possible because the coating tended to be completely absorbed into the concrete after cure without leaving any residue on the surface.

\subsection{Curing State of Silane Coatings}

Figure 7 shows the schematics explaining the formation of silane coating on concrete surface, according to Arkles [21]. Silane reacts with atmospheric moisture or water in pores present on the concrete surface. The silanol-containing groups in silane are then formed through hydrolysis of 
three alkoxy groups, followed by the condensation to oligomers. Covalent linkage or crosslinking finally takes place via bonding between the hydroxyl groups of silane and concrete during drying.

The DSC result in Figure 8 indicates the absence of exothermic peak, confirming that silane cannot be simply cured by thermal heating or hydrogen bond formation with water. This suggests that the curing process of silane and its formation of protective thin film on concrete surface require alkaline elements, e.g. $\mathrm{Ca}(\mathrm{OH})_{2}$, present in the cement. The endothermic peaks of these curves indicate that the evaporation temperatures were slightly different. Silane has a melting temperature of about $220^{\circ} \mathrm{C}$, and it increases to $235^{\circ} \mathrm{C}$ when it is mixed with water, due to limited crosslinking between the hydroxyl groups in silane and water, forming hydrogen bonds.

\subsection{Rheological Properties}

The changes in viscosity with time were monitored for different coatings, as shown in Figure 9, presenting quite steady viscosity values for all materials studied. The average values are summarized in Figure 10 as a function of clay content. The viscosity of neat silane was approximately $0.009 \mathrm{~Pa}$. After the incorporation of clay, the viscosity increased almost linearly with clay loading. More than two-fold increase in viscosity was noted with the addition of $5 \mathrm{wt} \%$

Cloisite 20A. The nanocomposites containing Cloisite 20A had higher viscosities than those with I.30P clay with the same clay content. The introduction of rigid clay particles into otherwise homogeneous liquid increased the viscosity, which is a measure of internal friction when sheared.

The lower viscosity of the nanocomposite containing I.30P clay also suggests an easier application as a coating than those made from Cloisite $20 \mathrm{~A}$. 


\subsection{Wetting Properties}

Microphotographs taken immediately after dispensing the droplets on the concrete surfaces are shown in Figure 11, presenting different wetting behaviours of the neat silane and nanocomposite coating. The neat silane permeated into the concrete immediately without leaving any residue, not allowing the measurements of contact angles or zero contact angle (Figure 11 (a)), suggesting the neat silane having the best wettability amongst all coatings studied. In contrast, the silane/clay nanocomposites formed clear droplets on the concrete surface with contact angles, $48.0^{\circ}$ for $5 \mathrm{wt} \%$ Cloisite 20A and $42.6^{\circ}$ for $5 \mathrm{wt} \%$ I.30P (Figure 11 (b) and (c)), suggesting the surface tension being lower for the silane/I.30P system than for the silane/Cloisite 20A system. A smaller contact angle translates into a larger work of adhesion, $\mathrm{W}_{\mathrm{a}}$, with a better wettability for the silane/I.30P coating system. The droplet size decreased congituously over time, with a gradual decrease in contact angle until the entire droplet was absorbed into the concrete. The absorption rates were different for the two silane/clay systems, and it took approximately $180 \mathrm{~s}$ and $80 \mathrm{~s}$ for complete disappearance of silane/Cloisite $20 \mathrm{~A}$ and silane/I.30P droplets, respectively. The contact angles were closely monitored as a function of time after dispensing, as shown in Figure 12. The silane/Cloisite 20A system exhibited a slower reduction in contact angle than the silane/I.30P system, which is consistent with the viscosity measurement (Figure 10): the former nanocomposite with a higher viscosity should take a longer time for absorption into the concrete. In summary, the higher absorption rate and smaller contact angle at time zero, together with the lower viscosity for the silane/I.30P nanocomposites makes it more favourable for coating applications.

\subsection{Surface Morphology of Concrete}


Typical SEM micrographs taken of concrete surfaces after coating applications are shown in Figures 13 and 14. It is clearly shown that the microvoids present on the plain concrete surface were filled with the coating material. Some large pores were also entirely covered by the nanocomposite coatings, where the coatings with different clay types exhibited similar surface morphologies. Less microvoids exposed on the concrete surface after coating application means that the absorption and permeation of liquid solvents or gases into the concrete are effectively reduced. The effect of clay content on the concrete surface morphology is further illustrated in Figure 14. The increase in clay contents not only resulted in more effective coverage of microvoids, but also lowered the surface roughness of the concrete, thus reducing the surface area to be exposed to the environment for absorption or permeation of liquids/gases.

\subsection{Barrier Properties}

\subsubsection{Moisture Permeability}

The moisture barrier properties of the neat silane and nanocomposite coatings with different clay types were studied using the water permeation test. The weight gains over exposure time for concrete with and without coatings are shown in Figure 15, and the corresponding moisture permeability calculated from the initial slopes of the weight gain curves is shown in Figure 16. The hybrid concrete and coating layers were fully saturated with water before putting into the testing chamber. Therefore, the cumulative weight gain represents the net moisture uptake by the desiccants contained in the dish. The weight gains for all specimens increased linearly at the beginning and reached a plateau at around $270 \mathrm{~h}$, except the nanocomposite coating containing $5 \mathrm{wt} \%$ Cloisite $20 \mathrm{~A}$ clay which showed a linear increase of weight gain even after some $550 \mathrm{~h}$ of 
exposure. The plateau saturation means that the full capability of desiccants inside the dish was reached and any additional moisture cannot be absorbed.

It is obvious that the presence of silane and nanocomposite coatings significantly reduced the moisture permeability. The hydrophobic nature of silane and coverage of microvoids present on the concrete surface by the coating (Figures 13 and 14) along with the excellent barrier characteristics of clay with inherently large aspect ratio [10] were mainly responsible for the sharply reduced moisture permeability. The barrier performance of the $5 \mathrm{wt} \%$ I.30P nanocomposite was only slightly better than the neat silane, whereas the barrier performance of $5 \mathrm{wt} \%$ Cloisite $20 \mathrm{~A}$ nanocomposite was almost twice better than the neat silane coating. This observation implies that I.30P with better wettability and lower viscosity does not necessarily improve the barrier performance of the coating more effectively than Cloisite 20A. The aspect ratio and dispersion of clay with the silane matrix, as well as the chemical interaction between the silane and different types of clay also contributed to different extents of moisture barrier performance.

\subsubsection{Resistance to Chloride Ingress}

The average chloride contents for the control specimen without coating and those with different types of coating are presented in Figure 17. The chloride contents were taken as an average over the depth up to $50 \mathrm{~mm}$ into the concrete of at least three specimens. The concrete without coating showed the highest chloride content of around $0.0023 \mathrm{wt} \%$ of concrete mass. The chloride content dropped significantly with the application of coating: the neat silane and nanocomposite coatings brought an improvement with $92 \%$ and $69 \%$ reductions in chloride content, respectively. The 
effectiveness of silane as chloride barrier has also been reported previously based on different measurement techniques $[2,3,22,23]$. One of the main reasons for the better performance of the neat silane than the nanocomposite is that the silane coating is present deep into the concrete whereas the nanocomposite remains as a thin coating on the surface. Figure 18 illustrates schematic drawings of effective penetration depths for different coatings. It is likely that when the coating was applied onto the concrete surface, the neat silane coating could penetrate deeper into the concrete than the nanocomposite because of the much lower viscosity of silane (0.009 compared to $0.02 \mathrm{~Pa} \cdot \mathrm{s}$, see Figures 10 and 11) and the absence of rigid fillers. This is again confirmed by the rapid absorption of silane droplets into the concrete during the wettability test in Section 3.4. The clay nanoparticles present in the thin nanocomposite surface coating did not contribute much to improving the barrier against chloride.

It should be noted that while chloride ingress can depassivate steel and initiate corrosion, the continuation of corrosion process requires oxygen and water as well [24]. While silane is more effective in delaying chloride penetration and hence provide better protection against corrosion initiation, the nanocomposite coating can effectively reduce the permeation of water and oxygen necessary for corrosion process in addition to the reduction in chloride diffusion. On the whole, the nanocomposite coating can be a more effective protective layer.

\section{Conclusions}

The barrier performance of neat silane and silane/clay nanocomposite coatings after accelerated weathering tests was evaluated. It was found that the microvoids present on the plain concrete 
surface were filled with coating materials. The elimination of microvoids due to coating means that the absorption and permeation of liquids or gases into the concrete can be effectively reduced. Both the neat silane and nanocomposite coatings significantly reduced the moisture permeability of concrete. The moisture barrier performance was better for the nanocomposites containing Cloisite 20 A clay than those with I.30P clay or the neat silane coating. Approximately $5 \mathrm{wt} \%$ is found to be the optimal Cloisite 20A clay content that gave rise to the lowest permeability. The salt spray test indicates that the application of the neat silane and nanocomposite coatings reduced the average chloride content by $92 \%$ and $69 \%$ respectively, compared to the uncoated concrete. The neat silane coating was able to permeate deeper into the concrete than the nanocomposite, indicating better chloride resistance performance of the neat silane.

\section{Acknowledgements}

The project was supported by the Research Grant Council of Hong Kong SAR (HKUST6184/03E). Technical assistance from the Advanced Engineering Materials Facility (AEMF) and the Materials Characterization and Preparation Facilities (MCPF), HKUST is appreciated.

\section{References}

[1] Basheer PAM, Chidiact SE, Long AE. Predictive models for deterioration of concrete structures. Constr Build Mater 1996;10:27-37.

[2] Kim JK, Mai.YW. High strength, high fracture toughness fibre composites with interface control-a review. Compos Sci Technol 1991; 41: 333-378.

[3] Ibrahim M, Al-Gahtani S, Maslehuddin M, Almusallam AA. Effectiveness of concrete surface treatment materials in reducing chloride-induced reinforcement corrosion. Constr Build Mater 1997;11:443-451.

[4] Yang CC, Wang LC, Weng TL. Using charge passed and total chloride content to assess the 
effect of penetrating silane sealer on the transport properties of concrete. Mater Chem Phys $2004 ; 85: 238-244$.

[5] Kojima Y, Usuki A, Kawasumi M, Okada A, Fukushima Y, Kurauchi T, Kamigaito O. Mechanical properties of nylon 6-clay hybrid. J Mater Res 1993;8:1185-1189.

[6] Lan T, Kaviratna PD, Pinnavaia TJ. Mechanism of clay tactoid exfoliation in epoxy-clay nanocomposites. Chem Mater 1995;7:2144-2150.

[7] Hackman I, Hollaway L. Epoxy-layered silicate nanocomposites in civil engineering. Compos Part A 2006;37:1161-1170.

[8] Woo RSC, Chen YH, Zhu HG, Leung CKY, Kim JK, Environmental degradation of epoxy-organoclay nanocomposites due to UV exposure: Part I Photodegradation, Compos Sci Technol 2007; 67: 3448-3456.

[9] Woo RSC, Zhu HG, Leung CKY, Kim JK, Environmental degradation of epoxy-organoclay nanocomposites due to UV exposure: Part II residual mechanical properties, Compos Sci Technol in review 2007.

[10] Kim JK, Hu CG, Woo RSC, Sham ML. Moisture barrier characteristics of organoclay-epoxy nanocomposites. Compos Sci Technol 2005;65:805-813.

[11] Kim JK, Lai MF. Effects of epoxy treatment of organoclay on structure, thermo-mechanical and transport properties of poly(ethylene terephthalate-co-ethylene naphthalate)/organoclay nanocomposites. Polymer 2005;46:4722-4734.

[12] Hu CG, Kim JK. Epoxy-organoclay nanocomposites: morphology, moisture absorption behavior and thermo-mechanical properties. Compos Interf 2005;12:271-289.

[13] Siddiqui NA, Woo RSC, Kim JK, Leung CKY, Munir A. Mode I interlaminar fracture behavior and mechanical properties of CFRPs with nanoclay-filled epoxy matrix. Compos Part A, 2007; 38: 449-460.

[14] Lebbai M, Kim JK, Yuen MMF. Effects of moisture and elevated temperature on reliability of interfacial adhesion in plastic packages. J Electr Mater 2003;32:574-582.

[15] Model specification for protective coatings for concrete: Appendix 4. Civil Engineering 
Department of Hong Kong Government. July 1994.

[16] ASTM E96: standard test method for water vapour transmission of materials. 1995.

[17] Mehta PK. Concrete in the marine environment. Elsevier Applied Science, UK, 1991.

[18] Schiessl P, Breit W. Monitoring of the depth-dependent moisture content of concrete using multi-ring electrodes. Concrete Under Severe Conditions: Environment and loading (Volume Two), E \& FN Spon., UK, 1995:964-973.

[19] Kumar BG, Singh RP, Nakamura T. Degradation of carbon fiber-reinforced epoxy composites by ultraviolet radiation and condensation. J Compos Mater 2002;36:2713-2721.

[20] Tjandraatmadja GF, Burn LS, Jollands MC. Evaluation of commercial polycarbonate optical properties after QUV-A radiation-the role of humidity in photodegradation. Polym Degrad Stab 2002;78:435-448.

[21] Arkles B. Tailoring surfaces with silanes. Chemtech 1977;7:766-778.

[22] Folker HW, Zhao TJ, Zhan HY. Establishment of an effective chloride barrier by water repellent impregnation. Proc. Int. Workshop on Durability of Reinforced Concrete under Combined Mechanical and Climatic Loads (CMCL), Qingdao, China, Oct 2005.

[23] Schueremans L, Gemert DV, Giessler S. Chloride penetration in RC-structures in marine climate: in site survey, analysis model and benefit of a preventive hydrophobic treatment. Proc. Int. Workshop on Durability of Reinforced Concrete under Combined Mechanical and Climatic Loads (CMCL), Qingdao, China, Oct 2005.

[24] McPolin D, Basheer PAM, Long AE, Grattan KTV, Sun T. Obtaining progressive chloride profiles in cementitious materials. Constr Build Mater 2005;19:666-673.

\section{Figure Captions}

Figure 1 Chemical structure of octyltriethoxysilane.

Figure 2 Chemical structures of organic modifiers in (a) Cloisite 20A (HT is Hydrogenated Tallow having around $65 \% \mathrm{C} 18,30 \% \mathrm{C} 16$ and $5 \% \mathrm{C} 14$ ) and (b) I.30P.

Figure 3 Experimental setup of moisture permeability test.

Figure 4 Specimen for salty water spray resistance test. 
Figure 5 XRD spectra of (a) pure Cloisite 20A and silane-clay nanocomposites containing (b) 1 $w t \%$, (c) $3 \mathrm{wt} \%$ and (d) $5 \mathrm{wt} \%$ of Cloisite $20 \mathrm{~A}$.

Figure 6 XRD spectra of (a) pure I.30P and silane-clay nanocomposites containing (b) $1 \mathrm{wt} \%$, (c) $3 \mathrm{wt} \%$ and (d) $5 \mathrm{wt} \%$ of I.30P.

Figure 7 Hydrolytic deposition of silane. After [23].

Figure 8 DSC curves of (a) silane and (b) silane mixed with water.

Figure 9 Viscosity profile over time for silane-clay nanocomposite coatings with different clay types and loadings.

Figure 10 Variations of viscosity for silane-clay nanocomposites as a function clay loading.

Figure 11 Photographs of single droplets on concrete surfaces of (a) neat silane and silane-clay nanocomposites containing (b) $5 \mathrm{wt} \%$ Cloisite $20 \mathrm{~A}$ and (c) $5 \mathrm{wt} \%$ I.30P.

Figure 12 Contact angle vs time for silane nanocomposites containing Cloisite 20A and I.30P nanoclays.

Figure 13 SEM microphotographs of (a) plain concrete and concrete coated with (b) neat silane, (c) $3 \mathrm{wt} \%$ Cloisite 20A nanocomposite and (d) $5 \mathrm{wt} \%$ Cloisite $20 \mathrm{~A}$ nanocomposite, all with the same magnification.

Figure 14 SEM microphotographs of (a) plain concrete; concrete coated with (b) neat silane; (c) silane $/ 5 \mathrm{wt} \%$ Cloisite 20A nanocomposite and (d) silane/10 wt\% Cloisite 20A nanocomposite, all with the same magnification.

Figure 15 Weight gains over exposure time for concrete samples with and without coatings.

Figure 16 Permeability of concrete samples with and without coatings.

Figure 17 Chloride contents of concrete specimens with and without coatings.

Figure 18 Schematic of effective penetration depths for neat silane and silane-clay nanocomposite coatings.

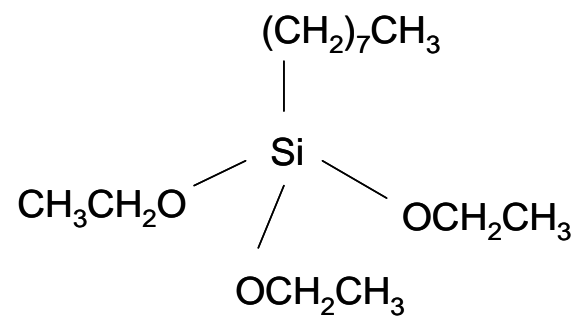

Figure 1 Chemical structure of octyltriethoxysilane.

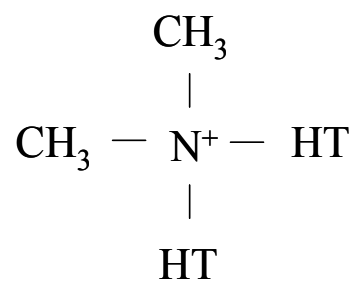

(a)

$$
\mathrm{CH}_{3}\left(\mathrm{CH}_{2}\right)_{16} \mathrm{CH}_{2} \mathrm{NH}_{2}
$$

(b)

Figure 2 Chemical structures of organic modifiers in (a) Cloisite 20A (HT is Hydrogenated Tallow having around $65 \% \mathrm{C} 18,30 \% \mathrm{C} 16$ and $5 \% \mathrm{C} 14$ ) and (b) I.30P. 


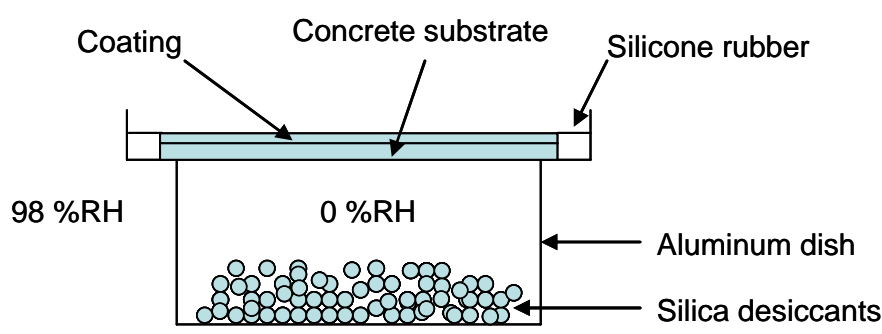

Figure 3 Experimental setup of moisture permeability test.

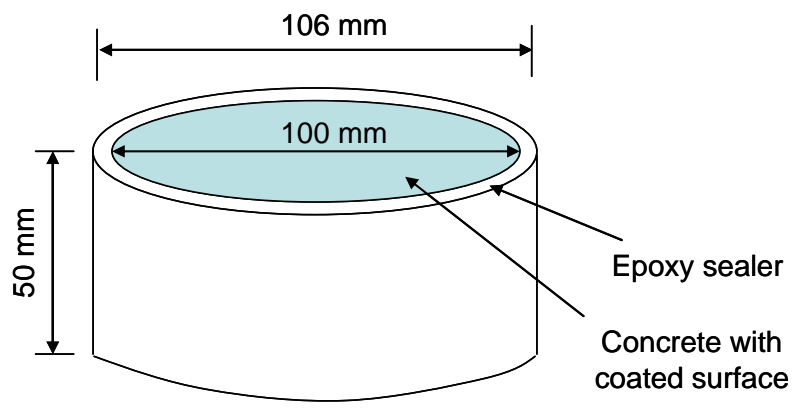

Figure 4 Specimen for salty water spray resistance test.

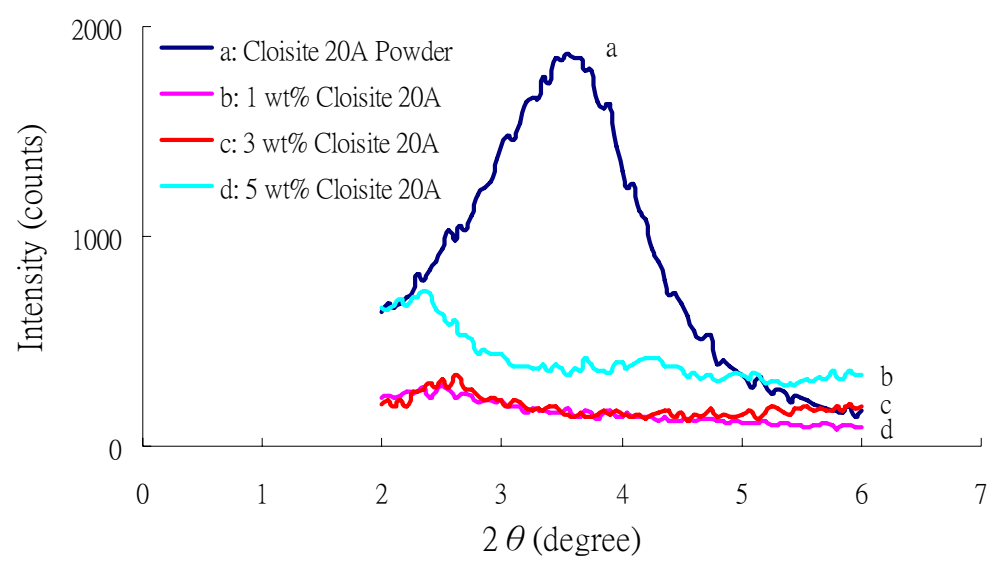

Figure 5 XRD spectra of (a) pure Cloisite 20A and silane/clay nanocomposites containing (b) 1 $\mathrm{wt} \%$, (c) $3 \mathrm{wt} \%$ and (d) $5 \mathrm{wt} \%$ of Cloisite $20 \mathrm{~A}$.

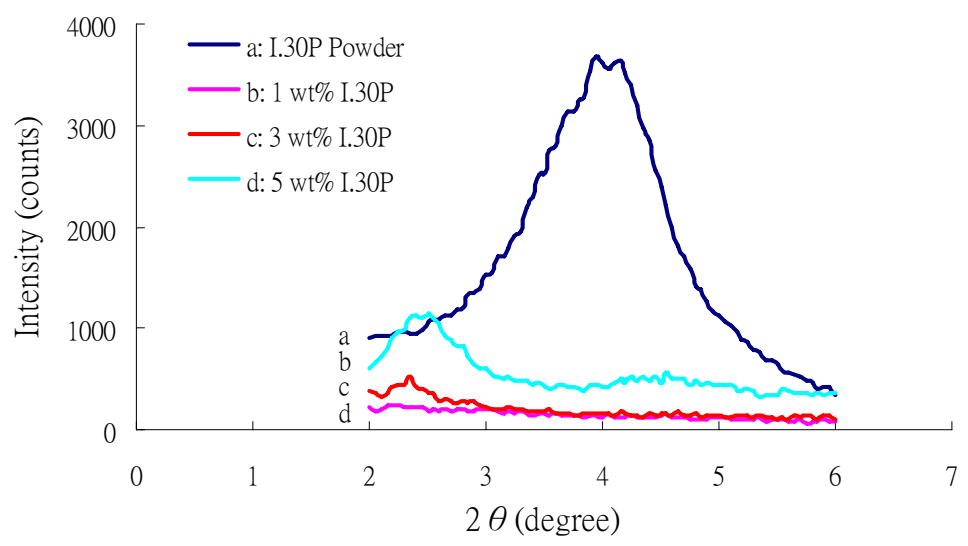

Figure 6 XRD spectra of (a) pure I.30P and silane/clay nanocomposites containing (b) $1 \mathrm{wt} \%$, (c) 3 wt $\%$ and (d) $5 \mathrm{wt} \%$ of I.30P. 

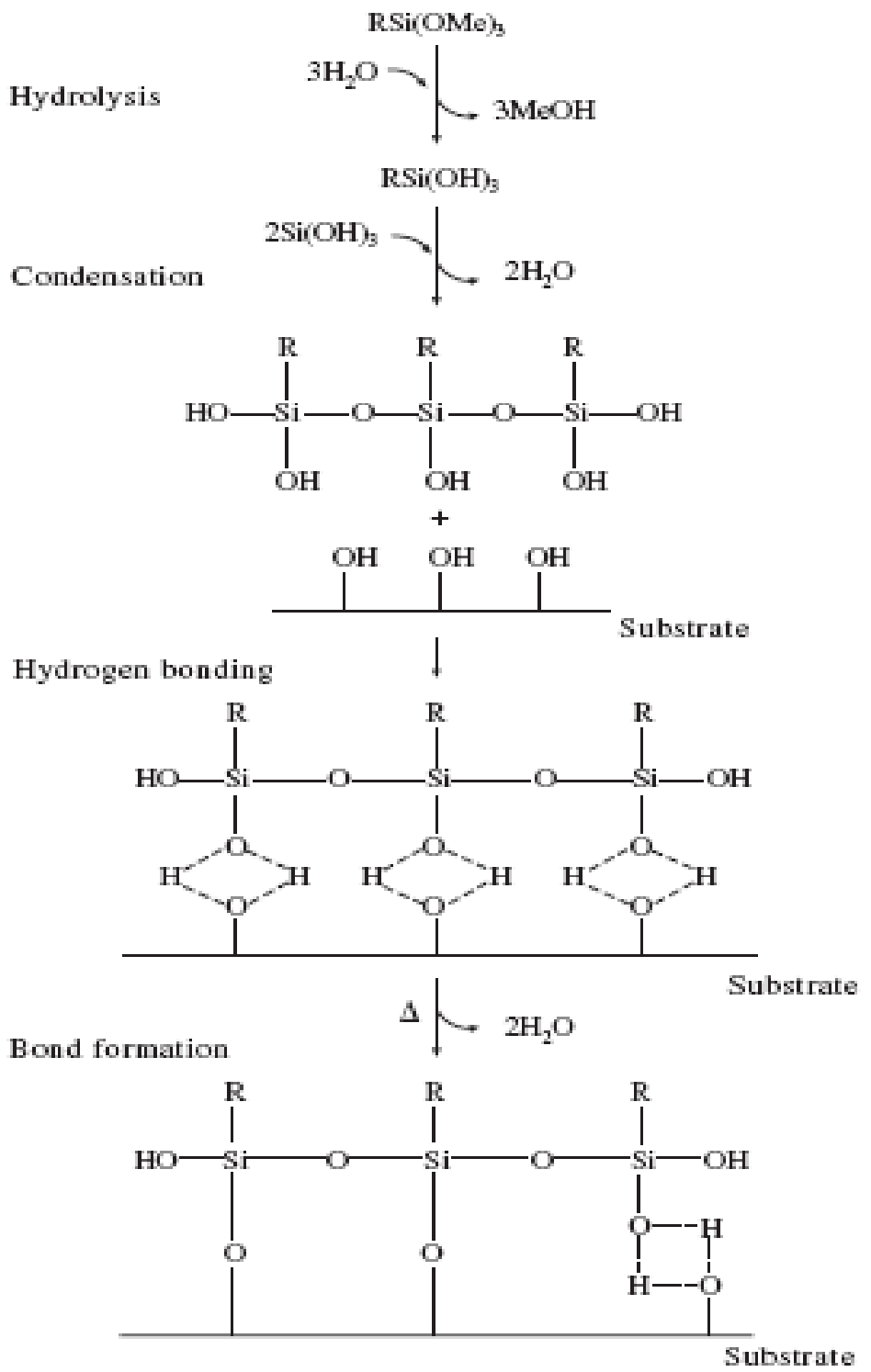

Figure 7 Hydrolytic deposition of silane. After [21].

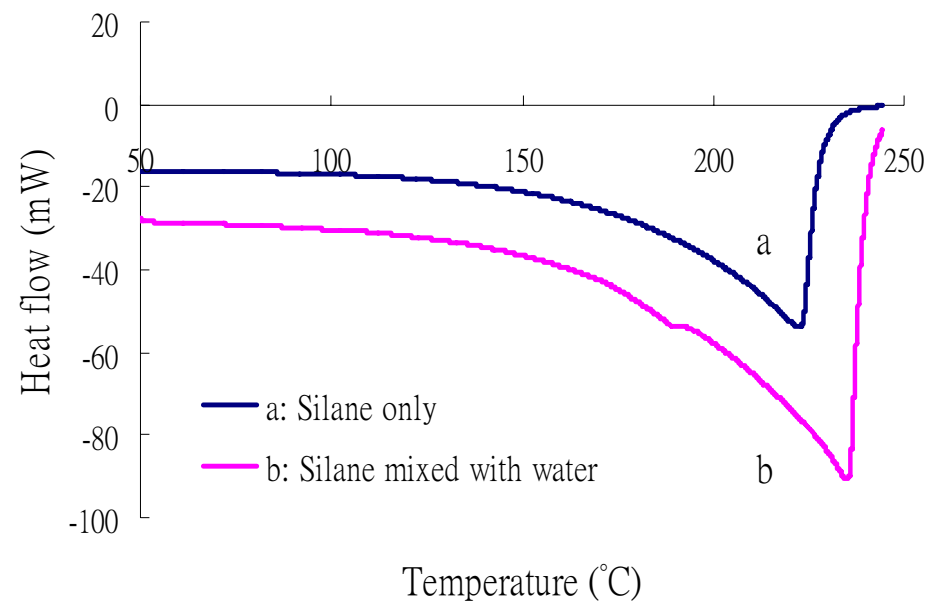

Figure 8 DSC curves of (a) silane and (b) silane mixed with water. 


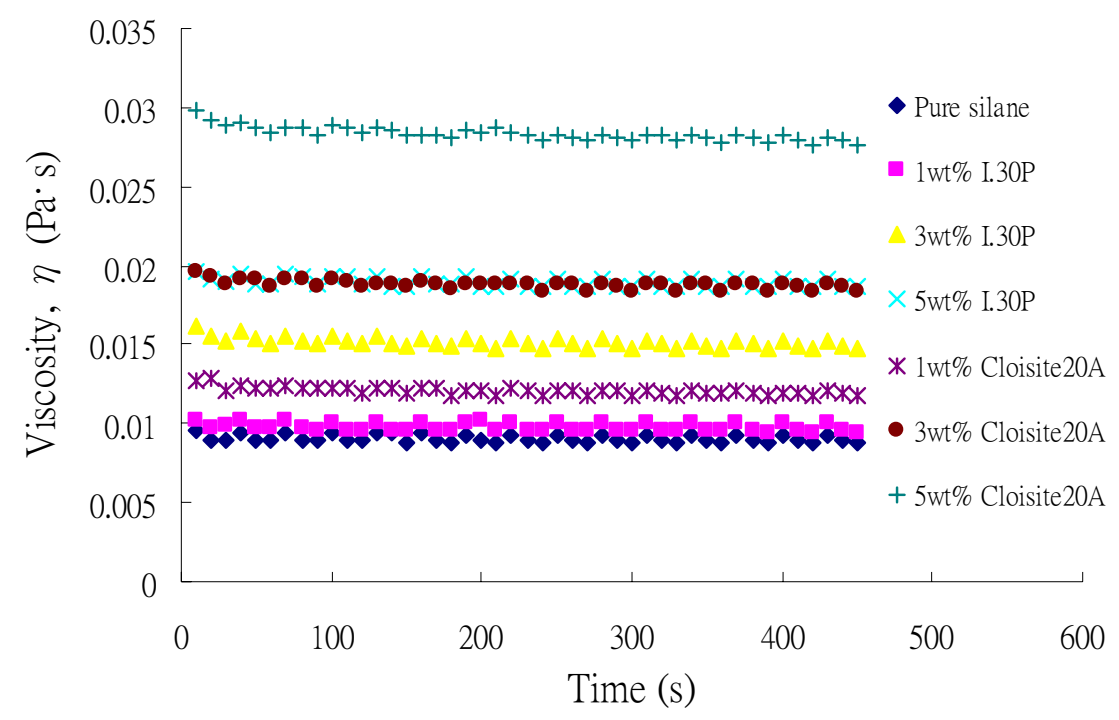

Figure 9 Viscosity profiles over time for silane/clay nanocomposite coatings with different clay types and loadings.

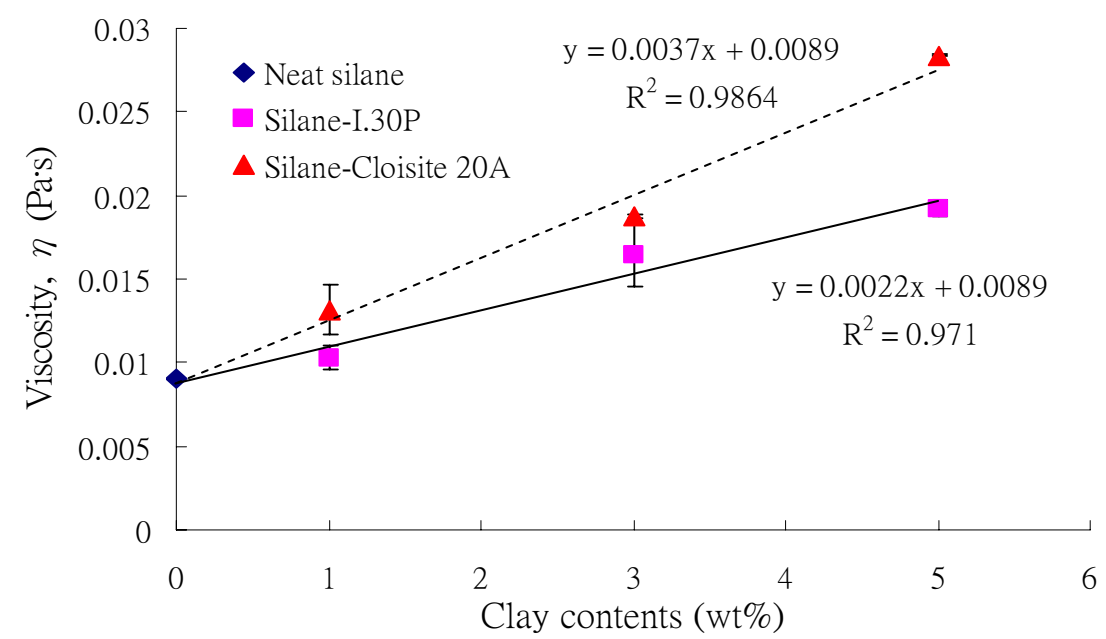

Figure 10 Variations of viscosity for silane/clay nanocomposites as a function of clay loading.

(a)

(b)

(c)

Figure 11 Photographs of single droplets on concrete surfaces of (a) neat silane and silane/clay nanocomposites containing (b) $5 \mathrm{wt} \%$ Cloisite $20 \mathrm{~A}$ and (c) $5 \mathrm{wt} \% \mathrm{I} .30 \mathrm{P}$. 


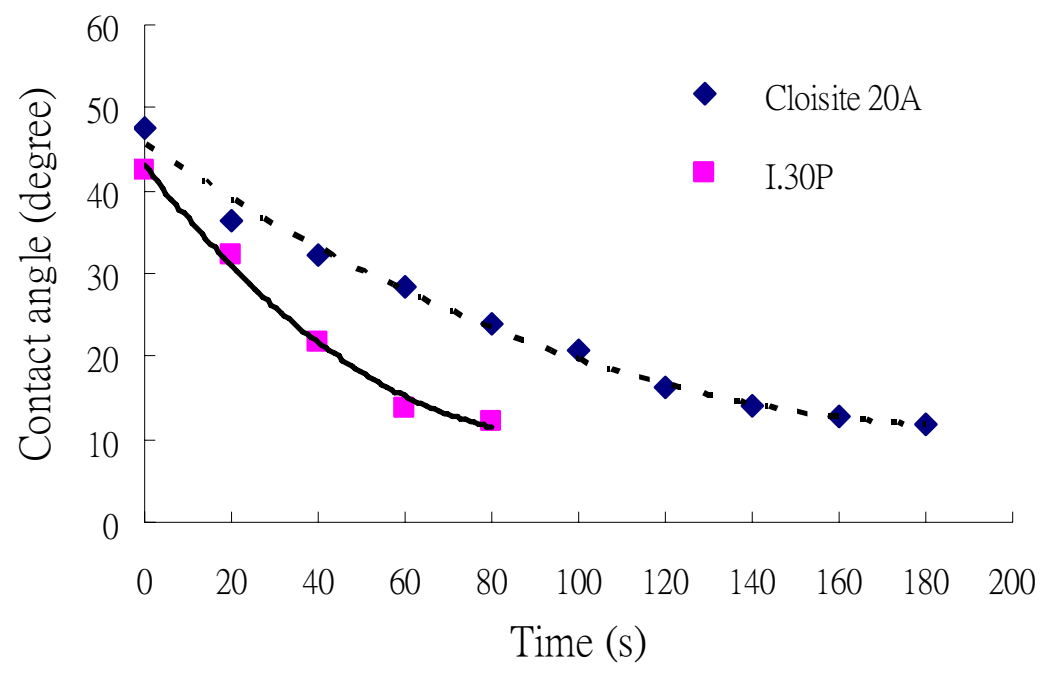

Figure 12 Contact angle vs time for silane nanocomposites containing Cloisite 20A and I.30P nanoclays.

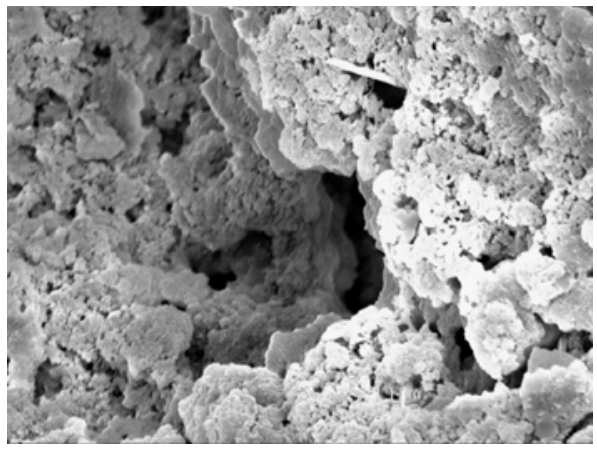

(a)

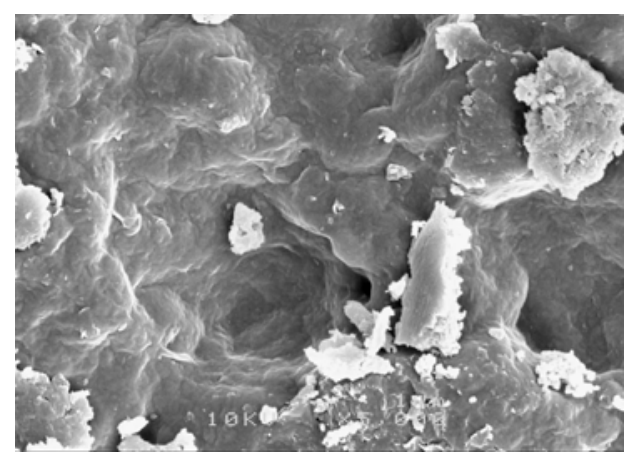

(c)

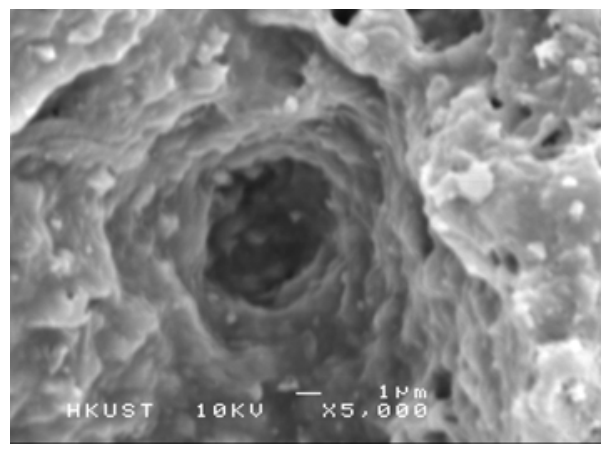

(b)

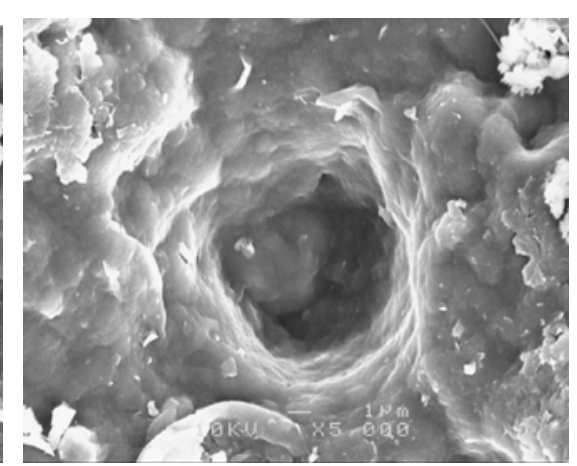

(d)

Figure 13 SEM microphotographs of (a) plain concrete and concrete coated with (b) neat silane, (c) $3 \mathrm{wt} \%$ Cloisite 20A nanocomposite and (d) $5 \mathrm{wt} \%$ Cloisite 20A nanocomposite. 


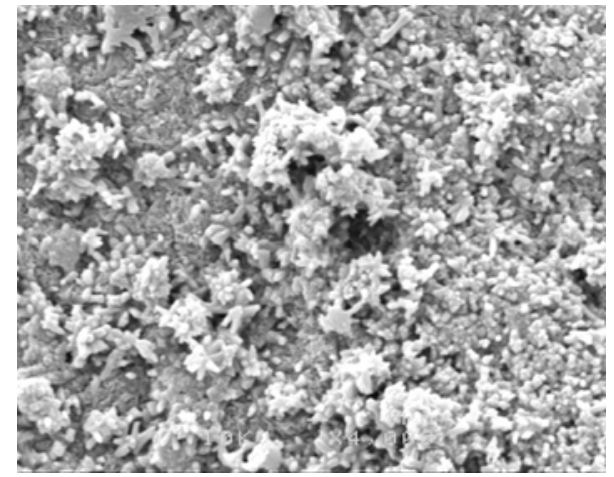

(a)

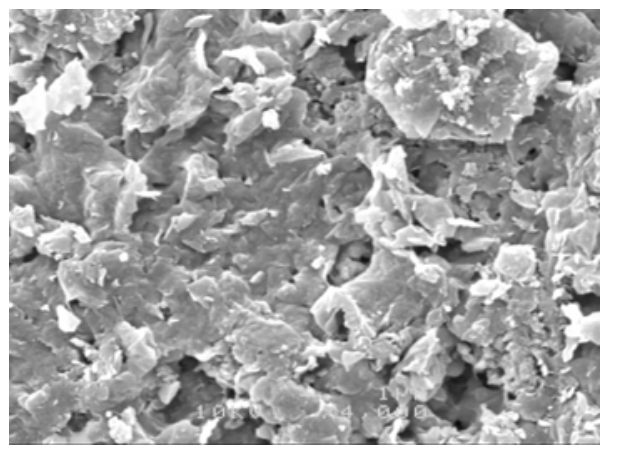

(c)

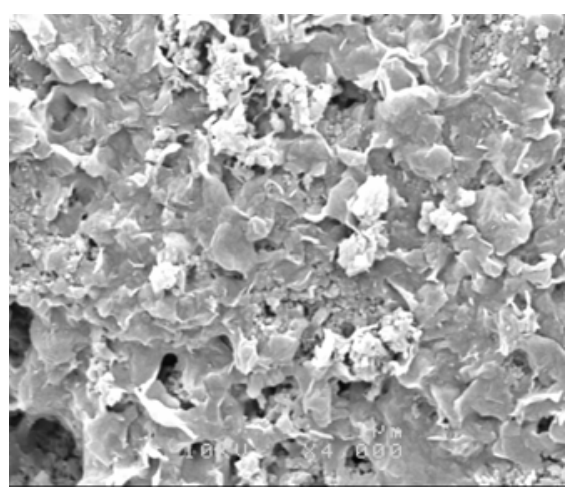

(b)

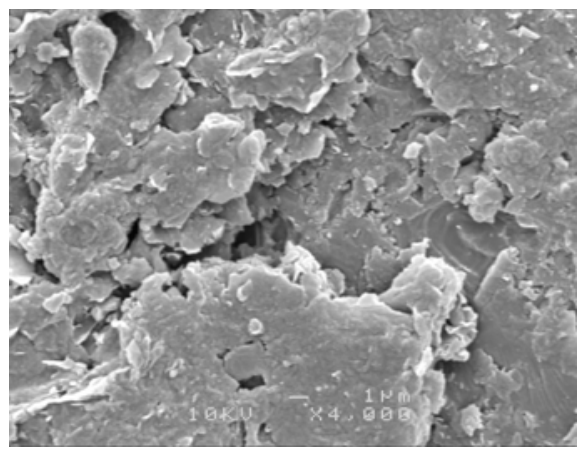

(d)

Figure 14 SEM microphotographs of (a) plain concrete and concrete coated with (b) neat silane, (c) $5 \mathrm{wt} \%$ Cloisite 20A nanocomposite and (d) $10 \mathrm{wt} \%$ Cloisite $20 \mathrm{~A}$ nanocomposite.

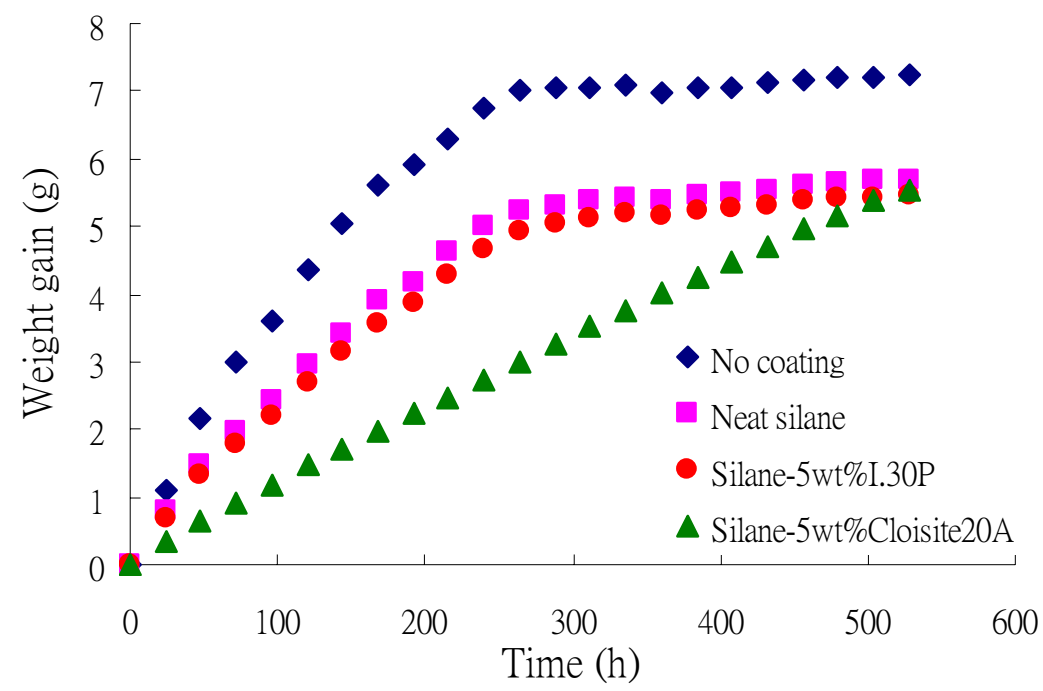

Figure 15 Weight gains over exposure time for concrete specimens with and without coatings. 


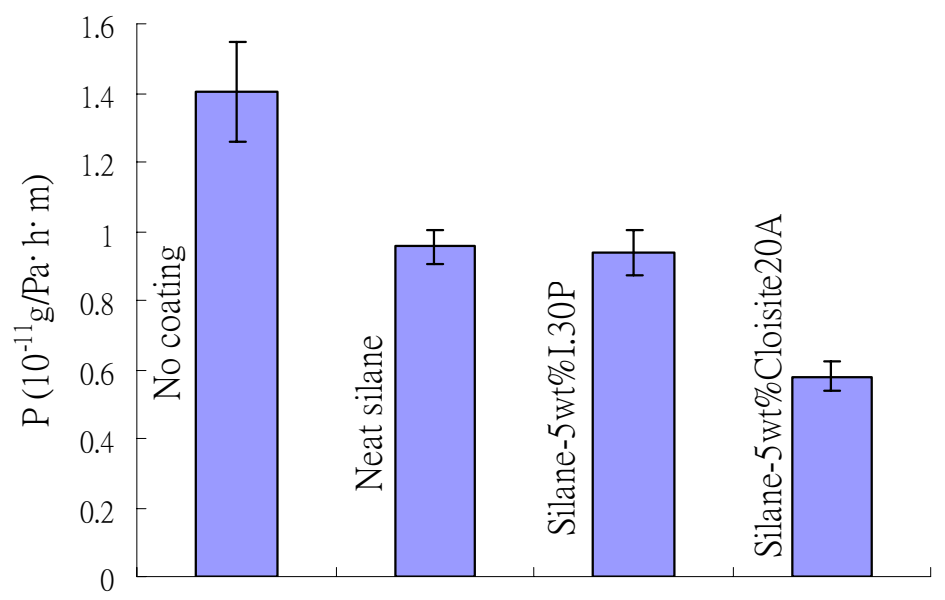

Figure 16 Permeability of concrete specimens with and without coatings.

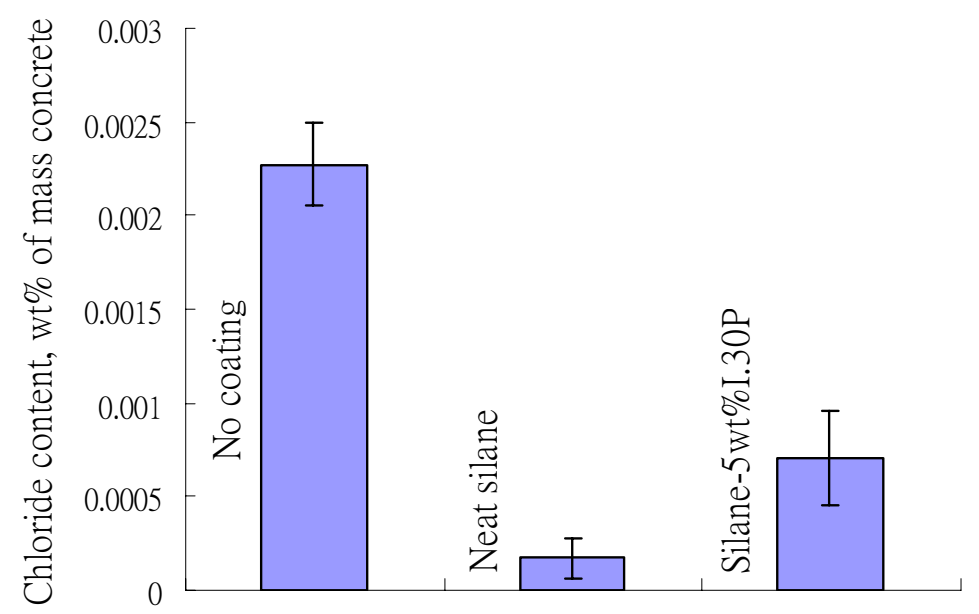

Figure 17 Chloride contents of concrete specimens with and without coatings.

Figure 18 Schematic of effective penetration depths for neat silane and silane/clay nanocomposite coatings. 